\title{
Housing First the conversation: discourse, policy and the limits of the possible
}

\author{
Amy S. Katz, Suzanne Zerger \& Stephen W. Hwang
}

Version Post-Print/Accepted Manuscript

Citation Amy S. Katz, Suzanne Zerger \& Stephen W. Hwang (2017) Housing

(published version) First the conversation: discourse, policy and the limits of the possible, Critical Public Health, 27:1, 139-147,DOI:

10.1080/09581596.2016.1167838

Publisher's Statement This is an Accepted Manuscript of an article published by Taylor \& Francis in Critical Public Health on 29 Mar 2016, available online: http://www.tandfonline.com/10.1080/09581596.2016.1167838.

How to cite TSpace items

Always cite the published version, so the author(s) will receive recognition through services that track citation counts, e.g. Scopus. If you need to cite the page number of the TSpace version (original manuscript or accepted manuscript) because you cannot access the published version, then cite the TSpace version in addition to the published version using the permanent URI (handle) found on the record page. 


\begin{abstract}
Researchers, policy-makers and political leaders in Canada and the US are championing the 'Housing First' (HF) intervention as a solution to homelessness. HF supplies people experiencing both homelessness and challenges around mental health with housing and a range of supports that can include case-coordination, psychiatry and primary care. While HF's impact on the housing status of individual participants has received considerable scientific and public consideration, less attention has been paid to its effects on societal conversations related to housing, public services and social justice. We explore some of the impacts, not of HF the intervention, but of HF the conversation - the way public documents related to HF interact with broader discourses. Specifically, we examine the potential for this conversation to undermine the ultimate goal of ending homelessness in Canada. We conclude that positioning program interventions - no matter how important in the current context - as singular solutions to issues like homelessness or preventable chronic disease risks obscuring distal causes and marginalizing systemic responses.
\end{abstract}

\title{
Key words
}

Housing First; discourse and health; social policy; homelessness; public health.

Journal section: Commentary 


\section{Introduction}

In recent years, researchers, policy-makers and political leaders in Canada and the US have championed 'Housing First' (HF) as a solution to homelessness (Klodawsky, 2009; Stanhope \& Dunn, 2011). HF is an intervention that supplies people experiencing both homelessness and challenges around mental health with housing and supports. In contrast to the traditional 'stepwise' approach, which requires people to complete treatment before attaining housing, HF does not compel participants to accept treatment or stop using substances (Tsemberis, 2010). Randomized controlled trials in Canada and the US have demonstrated that the majority of people who participate in HF programs achieve extended housing tenure (Tsemberis, Gulcur \& Nakae, 2004; Stergiopoulos et al., 2015).

While HF's impact on the housing status of individual participants has received considerable scientific and public (Dansky, 2014; Goodman, 2014) consideration, less attention has been paid to the effects of HF on societal conversations related to housing, homelessness, public sector services and social justice. Keith Jacobs and Tony Manzi (1996) explore how language has served to shape housing policy in the United Kingdom, pointing out that while '...there is... a tendency to assume that language is simply a representation of an underlying reality... language itself constitutes a part of how we form our world' ( $p$. 558). In other words, the way we talk about the world shapes the way we act in it. As a result, we choose to explore the impacts, not of HF the intervention, but of HF the conversation - the way in which articles, papers and policy documents related to HF interact with broader discourses. Specifically, we examine the potential for conversations related to $\mathrm{HF}$ to undermine the ultimate goal of ending homelessness in Canada. We focus on policy context from Canada and discourse from both Canada and the US, the countries in which it can be argued the formal HF approach originated (Waegemakers Schiff \& Rook, 2012).

Based on our involvement with a randomized controlled trial of HF, we have come to recognize both the promise and perils of the conversations that surround the program. Over the course of the trial, we have used some of the language we critique here. In this article, we would like to explore our own use of language and raise questions about the relationship between interventions research and broader societal discourse.

\section{Definitions}

\section{At Home/Chez Soi and the Pathways model of Housing First}

Across and within jurisdictions, the design of programs using the label of 'Housing First' (HF) can vary. In Canada, the At Home/Chez Soi randomized controlled trial measured and demonstrated its fidelity to the HF model as developed by Pathways to Housing in New York City (Tsemberis, 2010). The Pathways model of HF offers people experiencing homelessness and challenges around their mental health access to independent housing with no treatment related pre-conditions (people do not have to stop using 
substances or accept treatment, although they are required to meet with a case manager weekly), and off-site supports. People assessed as having moderate needs have access to a case manager who coordinates external services. People assessed as having higher needs have access to a range of direct supports including case management and psychiatric and primary care, offered through Assertive Community Treatment Teams (Nelson, Aubry \& Lafrance, 2010). The program also enshrines a long-term commitment to participants. If people lose their housing or choose to move, they can be re-housed, often several times, and supports follow program participants wherever they end up living.

When we reference HF, we are referring to the Pathways model of HF - At Home/Chez Soi in the context of Canada. Where we have not examined fidelity to the Pathways model or where we are bundling together references to a number of programs, we refer to 'HF-type' programs.

\section{Obscuring hidden homelessness and housing instability}

HF-type programs are often broadly framed as interventions that will end or solve homelessness (Gladwell, 2006). They are frequently (although not exclusively) targeted, however, at a particular category of people experiencing homelessness: single adults who experience mental health problems

and who are visibly or 'chronically' homeless.' In Canada, the category of 'chronic homelessness' is applied by federal policy-makers to people who have been homeless for designated periods of time, 'often with disabling conditions' such as what are classified as serious mental health problems, physical illnesses or problems with substances (Employment and Social Development Canada, 2014). HF trial protocols in both Canada and the US have defined chronic homelessness in related terms, focusing on adults with histories of homelessness and diagnosable mental health conditions (Tsemberis, Gulcur \& Nakae, 2004; Goering et al., 2011).

Researchers, advocates and service providers have pointed out that the construction of and focus on the label of 'chronic homelessness' can draw attention away from the homelessness of those who do not fit the category (Schrank, 2013; Heffernan, Todorow \& Luu, 2015). As one example, some have raised the concern that the deployment of the category of 'chronic homelessness' in Canada could obscure the visibility of women and families who are homeless, and therefore divert funding away from programs for these groups:

Couch surfing, doubling up with other families in conditions of extreme overcrowding, cycling in and out of abusive relationships, trading sex for temporary accommodation, and other survival strategies that homeless women deploy have generally been categorized as indicative of "relative [as opposed to chronic or absolute] homelessness." (Homes for Women Campaign, 2013, p. 5)

More generally, an exclusive focus on chronic homelessness can serve to obscure the large number of people in Canada who live in housing that is unaffordable, unsafe, overcrowded and/or poorly 
maintained (Research Alliance for Canadian Homelessness, Housing and Health, 2010; Wellesley Institute, 2010; Paradis, Wilson \& Logan, 2014; Heffernan, Todorow \& Luu, 2015).

\section{Suggesting that programs can function in a policy vacuum}

The frequent emphasis on HF's ability to 'end homelessness' can also imply that HF functions in a policy vacuum. In the Canadian context, however, HF has complex relationships with both the public sector and the private rental market. For example, HF - while developing some its own infrastructure - relies on the existence of a public health care system and existing networks of largely publicly-funded community services. Further, as many people participating in HF receive income supplements, the level of assistance provided by, for example, disability programs, will have a profound effect on their daily lives. In addition, HF relies on private market housing, establishing a permanent relationship with what is, in many Canadian cities, a limited supply of what can be weakly regulated, often poorly maintained rental stock (Wellesley Institute, 2010; Paradis, Wilson \& Logan, 2014). Tellingly, a lack of affordable quality housing has been flagged as an obstacle to HF implementation Canada-wide (Goering et al., 2014). ${ }^{\text {ii }}$

This context, however, is so often marginalized in public conversations related to $\mathrm{HF}$ that researchers in Canada have taken to repeating that the program is, 'not a silver bullet' (Nolais, 2012; Swan, 2013), and should be considered but one component of a strategy that: builds new affordable housing; addresses all groups experiencing homelessness or housing instability; includes a range of quality supportive housing options; and, pays attention to factors that generate poverty. More generally, researchers have cautioned that leaving policy context out of HF-related research and conversations can lead to the 'overgeneralization of research results' across jurisdictions (Johnsen \& Teixeira, 2010).

These 'silver bullet' narratives can obscure the complex web of factors that facilitate or detract from the success of HF itself. More broadly, silver bullet narratives imply that program interventions have the potential to solve large-scale societal problems on their own, potentially drawing attention and support away from the very policy solutions that might serve to transform conditions. For example, if $\mathrm{HF}$ is a solution to homelessness it is, by implication, a solution to Canada's lack of affordable housing. Many Canadian jurisdictions, however, are implementing the program in the context of ongoing public disinvestment from and/or inadequate new investment in affordable housing (Klodawsky, 2009; Gaetz, Gulliver \& Richter, 2014; Heffernan, Todorow \& Luu, 2015). When program interventions are posited as 'solutions' to macro issues, this can obscure these incidences of broader disinvestment from public infrastructure (Meyer \& Schwartz, 2000).

\section{Positioning homelessness as a disease vs. something that is produced by a system}

Many have argued that current mainstream narratives frame homelessness as (at best) a disease, focusing attention on afflicted individuals rather than on a system that consistently produces both homelessness and housing instability. Susan Finley and Marcelo Diversi (2010) write that homelessness 
and prosperity can only co-exist, '...because the dominant discourse continues to imagine it as an individual problem, deficiency, shortcoming or illness' (p. 12). Craig Willse (2010) writes that, 'chronic homelessness initiatives neglect structural forces' (p. 168), and shares this critique as framed by a US advocacy organization:

The term "chronic homelessness" treats homelessness with the same language, and in the same fashion, as a medical condition or disease, rather than an experience caused fundamentally by poverty and lack of affordable housing. (National Coalition for the Homeless, 2002, as cited in Willse, 2010)

Evidence, however, demonstrates that homelessness and housing instability in cities in Canada are produced by 'dehousing processes and mechanisms' (Hulchanski, 2009, p. 4), and are generally associated with decisions made by policy-makers, landlords and employers, the impacts of which can be measured over time. These include but are not limited to government disinvestment from social housing and associated shortages (Gaetz, Gulliver \& Richter, 2014); shortages of quality assisted housing units (Centre for Addictions and Mental Health, 2014); shortages of quality, affordable, private market rental housing (Paradis, Wilson \& Logan, 2014) and related policies such as inadequate inspection regimes (Slater, 2004; Paradis, Wilson \& Logan, 2014) and processes such as neighbourhood gentrification (Slater, 2004; Institute for Children, Poverty \& Homelessness, 2013); iiirates for social assistance, including disability assistance, set below the cost of living (Gaetz, Gulliver \& Richter, 2014); inadequate and badly fragmented mental health supports (Canadian Alliance on Mental Illness and Mental Health, 2006); unlivable minimum wages (Monsebraaten, 2014); and the prevalence of low wage, precarious work (Lewchuck et al., 2013).

Many have pointed out that power relations themselves are fundamental or 'distal' causes of public health problems (Beauchamp, 1976). For example, evidence is clear that entrenched, interrelated drivers of injustice in Canada including but in no way limited to colonialism (Baskin, 2007; Allan \& Smylie, 2015), racism (Ornstein, 2006; Baskin, 2007; Levy, Ansara \& Stover, 2013; Allan \& Smylie, 2015), homophobia and transphobia (Abramovich, 2012), and misogyny (Centre for Research on Inner City Health, 2014) have direct impacts on health and impact access to both health care and determinants of health, including stable, quality housing. ${ }^{\text {iv }} \mathrm{All}$ of these factors operate in dynamic interaction with the policies and decisions listed in the above paragraph, manufacturing scarcity, marginalization and preventable ill health.

The framing of 'chronic homelessness,' however, places an emphasis on the affliction of individuals (Meyer \& Schwartz, 2000), thereby positioning itself to explore and take on proximate causes - the immediate factors that perpetuate the type of homelessness targeted (lack of rent money, addictions and/or diagnosable mental health conditions). The intervention produced by this framing - rent supplements and access to treatment and supports for some percentage of a defined group of people who have already experienced long histories of homelessness - is absolutely necessary in the current 
Canadian context. As David R. Williams and Chiquita Collins (2001) point out, however, interventions that focus on proximate causes have little hope of making transformative change. The HF program does not have the capacity to challenge the current context - to reach towards fundamental causes and prevent the production of poverty and homelessness in the first place.

On a discursive level, a focus by researchers on proximate causes can take attention away from fundamental causes that predictably reproduce not just any one problem, but, rather, a host of negative outcomes (Meyer \& Schwartz, 2000; Williams \& Collins, 2001; O'Campo \& Urquia, 2012). Nancy Krieger (1994) suggests that a type of helplessness around the possibility of transformative change can set in when fundamental causes are not placed in the foreground. Evoking the 'web of causation' - a common epidemiological model depicting the 'complex relationships among risk factors' for disease - Krieger asks us to think less about the web and more about the spiders. Without them, there is no-one to hold to account for the shape of the web, and nothing to be done to alter its fundamental contours.

There are other, related discursive pitfalls associated with the framing of 'chronic homelessness.' If we see chronic homelessness as akin to a medical condition, we will naturally conclude that only those suffering from this medical condition should receive treatment. Put another way, narratives that bind 'real' homelessness (i.e., chronic homelessness) to sickness imply that people need and deserve assistance in the form of housing because they are sick. Everyone else, it would follow, should be able to get by without much public help, or does not deserve it. This dichotomy can then be, '...deployed to minimize the provision of services to those individuals who do not fit a very narrow definition of what it means to be homeless' (Del Casino \& Jocoy, 2008, p. 192). This logic reflects broader discursive and policy trends in Canada and the US, where financial assistance is increasingly reserved for those with diagnoses of chronic illness (Pulkingham \& Fuller, 2012; Hansen, Bourgois \& Drucker, 2014).

Victoria Stanhope and Kerry Dunn (2011) point out that targeting specific groups for assistance can imply that welfare policies should be 'selective rather than universal,' setting up a situation that encourages researchers to identify, '....individual decontextualized areas of need that are not taken care of by the market' (p. 279). By identifying these 'decontextualized areas of need' researchers (willingly or not) implicitly assent to the idea that all but those classified as sick or somehow pathologically needy (and able to provide 'proof' of these claims) should be able to prosper in the context of the free market. Narratives embedding the idea that most people should be able to function on the basis of their own purchasing power can, in turn, be used to support the erosion of public services like health care and housing, coming full circle to focus much reduced public resources on 'decontextualized' interventions to address proximate causes.

\section{Implying 'there is not enough to go around'}

Many documents - including essays (Gladwell, 2006), academic articles (Culhane, Metraux \& Hadley, 2002), and reports (Goering, et al., 2014) - emphasize the potential of HF-type programs to generate savings related to public services. While these claims are often accurate, their frequent repetition can 
serve to construct the scarcity of public resources as a fact, instead of the result of a series of political and economic decisions. In his article in the New Yorker, 'Million Dollar Murray,' Malcolm Gladwell (2006) writes:

But the Denver homelessness program doesn't help every chronically homeless person in Denver. There is a waiting list of six hundred for the supportive-housing program; it will be years before all those people get apartments, and some may never get one. There isn't enough money to go around, and to try to help everyone a little bit-to observe the principle of universality-isn't as cost-effective as helping a few people a lot. Being fair, in this case, means providing shelters and soup kitchens, and shelters and soup kitchens don't solve the problem of homelessness. Our usual moral intuitions are little use, then, when it comes to a few hard cases. Power-law problems leave us with an unpleasant choice. We can be true to our principles or we can fix the problem. We cannot do both.If, in fact, there isn't 'enough money to go around,' this is true because a series of decisions have made it so. A scarcity of resources for public wellbeing - twinned with enormous concentrations of personal wealth, as is the case in Canada and the US (Conference Board of Canada, 2013; Ratner, 2014) - is not an inevitability. There are other ways to do things; the reader is presented with a false choice.

Krieger (1994), discussing the use of the word 'environment' to explore contextual factors that lead to disease, makes an argument against this type of implicit determinism:

In rejecting this analogy, it would make clear that social conditions are not 'natural' but are constructed by people, with purpose in mind and accountability an option. (p. 899)

\section{Positioning cost recovery as a primary goal of social policy}

The frequent association between HF programs and cost recovery can also suggest that cost recovery should be a primary goal of homelessness programs, and of social policy in general. Even after explaining that the Denver program will leave some people waiting years - or forever - for housing, Gladwell writes, 'we can be true to our principles or we can fix the problem.' With this statement, Gladwell can be interpreted as framing cost rather than homelessness as the principle issue at hand. Stanhope and Dunn (2011) point out that this framing can have concrete policy impacts:

The reliance on the argument that a problem is costly and visible creates strange incentives within policy making, implying that less costly and less visible problems will not make it onto the policy agenda... By setting the debate in terms of costs rather than other interest and values, advocates are vulnerable when the cost analysis does not come out in their favour. (p. 280)

Stanhope and Dunn write that this type of argument has implications for the very nature of public policy and discourse, writing that, 'Market values take on a hegemonic quality replacing all other values' ( $p$. 280). As a result, it is not simply that researchers have learned to frame our asks using the terms of a value-neutral discourse that appeals to policy-makers. Nor is it the case that all means necessarily have the capacity to lead to the same ends. Instead the means - embedding the case for 'solutions' in a market-based logic - can affect the ends, perhaps allowing for bumps of progress at the level of 
proximate causes, while potentially marginalizing macro-level interventions and transformative discourses with the potential to get closer to at least some basic causes.

\section{Limitations}

As we are exploring the ways in which 'HF the conversation' may undermine the ultimate goal of ending homelessness, we do not focus on its positive effects, of which there are many. Chief among them is the promotion of harm reduction as a legitimate approach to health and social services in Canada. In its embrace of harm reduction, HF represents an important paradigm shift, one that has the potential to reach beyond HF programs themselves. It can also be argued that HF has helped to intensify the discussion about homelessness in Canada, and assisted in undermining the idea that widespread absolute homelessness in cities is just a 'fact of life.' HF can also be seen to acknowledge and bring light to the complex trauma and chronic illness dealt with by many people experiencing homelessness. Most saliently, the emphasis on HF has translated into funding and support for HF-type programs from different levels of government (Ostroff, 2015).

It should also be noted that current funding does not come close to meeting the needs of people who are 'chronically homeless' in Canada. Our goal with this paper, however, is not to explore the degree to which HF or other programs have been implemented in Canada or other jurisdictions. Rather, we posit that related conversations are a type of intervention in and of themselves, with potential impacts that are traceable independent of HF programs.

Finally, this work is limited in that it reflects our views on the current research and policy discourse and some of the structural roots of preventable health problems. By focusing on the conversations and structures that perpetuate inequity, we may have unintentionally obscured the broad range of work that mitigates and pushes back against systemic inequities and nurtures systems of knowledge, discourse, care and activity distinct from those critiqued in this paper.

\section{Conclusion}

Our preference would be to end this paper with a set of recommendations for health researchers focused on interventions. Unfortunately, there are no guidelines for navigating the complex realities we face. On one hand, we see any number of crises, corners of which can be addressed through discrete health care and social service interventions we have the capacity to design, implement, evaluate and promote. This is not a small thing. For example, at the At Home/Chez Soi trial's Toronto site, permanent housing and supports were secured for 240 people, with additional funding for hundreds if not thousands more coming online. On the other hand, evidence makes clear that many of these crises be they related to homelessness or chronic disease or both - could be avoided through transformative 
shifts and systems-level changes. To complicate matters, systems-level decisions with the potential to aggravate or alleviate these same crises are being made in real time. The discourse is also ever-shifting, helping to shape the way we see ourselves and each other, and impacting both systemic realities and personal decisions and interactions.

Although we cannot provide a set of guidelines, we can share some cautions. Simply put, it is essential that vital program interventions are not posited as answers to problems like homelessness or chronic disease in the context of government inaction on or disinvestment from macro-level solutions. It is also essential that intervention-related 'solutions' are not used to sidestep the overlapping ways in which colonialism, racism, misogyny and other injustices structure Canadian society. While the fundamental renegotiation of societal relationships might be seen as outside the purview of some health interventions research (although this does not have to be so), our work should not be used to obscure the fact that this renegotiation needs to take place.

We would also like to note that, as a result of our professional locations at the nexus of public health research and policy, it has been relatively easy for us to slip reflexively into some of the language we have highlighted here. If we were working more closely with grassroots groups around our use of language, and consulting more broadly about the discursive issues we raised here, it is possible we might have avoided some of the pitfalls of the 'Housing First the conversation.' At the very least, we would have found ourselves more directly accountable to stakeholders beyond those working in funding, research and policy.

At the same time, we wish to acknowledge that there are compelling reasons for researchers to tap into some of the discourses we critique here. For example, we have repeatedly used - and continue to use cost-effectiveness arguments in our work. As we hope we have demonstrated in this paper, however, these arguments - no matter how effective in the service of specific goals - reverberate beyond our funding applications and research reports, and can have ripple effects that exacerbate the very problems our research and programs are trying to solve.

Sometimes, allowing space to 'not know' can be as powerful as coming to a conclusion. We are hoping this is one of those times, as we cannot share a definitive prescription for the questions we've raised. As participants in 'Housing First the conversation,' there will still be moments at which we will choose to emphasize, for example, cost recovery. There will also be opportunities to crack open the story, to provide additional context, to describe and go after fundamental causes of homelessness and ill health. We are all participating in defining the terms of the debate, and the limits of the possible. The parameters have not been set in advance.

\section{End notes}

i. It should be noted that HF is not appropriate for all people classified as 'chronically homeless.' A range of supportive housing options are needed in Canada, including in some cases those with higher supports (Stergiopoulos et al 2010; Goering et al, 2014, p. 20 ). 
ii. The degree to which HF interacts with and impacts other publicly-funded programs is explored in a policy brief by Matthew Stock (2016) from the Canadian Centre for Policy Alternatives, released as this paper was going through the review process. For example, Stock discusses the fact that, in some cases, funding has been diverted from services such as meal programs and shelters to resource HF, impacting the broader community as well as potentially HF participants themselves. The brief, Ending Homelessness? A Critical Examination of Housing First in Canada and Winnipeg, also illustrates several other points made in this commentary, including the potential of the language of 'chronic homelessness' to obscure other types of homelessness and housing instability.

ii. Many have suggested a relationship between processes of gentrification and HF-like interventions themselves, in particular in rapidly gentrifying inner cities in Canada such as Toronto (McQuaig, 2007; Clarke, 2008; Klodawsky, 2009).

iv. It is important to underline that, although certain determinants will apply to everyone, the 'social determinants of health' cannot be seen as a generic concept. For example, as Cyndy Baskin (2007) writes about Indigenous youth in Toronto, '...to adequately address determinants faced by Aboriginal youth, a framework that is culturally appropriate and addresses colonization needs to be implemented' (p. 31).

\section{References}

Abramovich, I.A. (2012). No safe place to go: LGBTQ youth homelessness in Canada: Reviewing the literature, Canadian Journal of Family and Youth, 4(1), 29-51.

Allan, B., Smylie, J. First Peoples, Second Class Treatment: The role of racism in the health and well-being of Indigenous peoples in Canada. (2015). Toronto: The Wellesley Institute. Available at: www.wellesleyinstitute.com/wp-content/uploads/2015/02/Summary-First-Peoples-Second-Class$\underline{\text { Treatment-Final.pdf }}$

Baskin, C. (2007). Aboriginal youth talk about structural determinants as the causes of their homelessness, The First Peoples Child \& Family Review, 3(3), 31-42.

Beauchamp, D.E. (1976). Public health as social justice, Inquiry, 13(1), 1-14.

Canadian Alliance on Mental Illness and Mental Health. (2006). Framework for action on mental illness and mental health: Recommendations to health and social policy leaders of Canada for a National Action Plan on mental illness and mental health. Available at: http://www.cpa.ca/cpasite/UserFiles/Documents/Practice Page/Framework for Action 2006.pdf

Clarke, J. (2008, August 27). 'Streets to Homes' drives out Toronto's poor. Rabble. Available at: http://rabble.ca/news/streets-homes-drives-out-torontos-poor 
Centre for Addictions and Mental Health. (2014). Housing Policy Framework. Available at:

www.camh.ca/en/hospital/about camh/influencing public policy/Documents/HousingPolicyFramewor

k FINAL2014.pdf

Centre for Research on Inner City Health, St. Michael's Hospital. (2014). Finding home: the impacts of partner violence on women's housing stability, health and wellbeing. Available at:

www.stmichaelshospital.com/crich/wp-content/uploads/Finding-Home-Feb-2014FINAL.pdf

Conference Board of Canada. (2013). Income inequality. Available at:

www.conferenceboard.ca/hcp/details/society/income-inequality.aspx

Culhane, D.P., Metraux, S. \& Hadley, T. (2002). Public service reductions associated with placement of homeless persons with severe mental illness in supportive housing, Housing Policy Debates, 13(1), 107163.

Dansky, K. (2014, October 23). This city came up with a simple solution to homelessness: housing. The Nation. Available at: www.thenation.com/article/184017/city-came-simple-solution-homelessnesshousing

Del Casino, V.J. \& Jocoy, C.L. (2008). Neoliberal subjectivities, the "new" homelessness, and struggles over space of/in the city, Antipode, 40(2), 192-199.

Employment and Social Development Canada. (2014). Homeless strategy partnering directives, 2014 2019. Available at: $w$ ww.esdc.gc.ca/eng/communities/homelessness/funding/directives.shtml

Finley, S. \& Diversi, M. (2010). Critical homelessness: expanding narratives of inclusive democracy, Cultural Studies - Critical Methodologies, 10(1), 4-13.

Gaetz, S., Gulliver, T., \& Richter, T. (2014). The State of Homelessness in Canada: 2014. Toronto: The Homeless Hub Press. Available at: www.homelesshub.ca/sites/default/files/SOHC2014.pdf

Gladwell, M. Million-dollar Murray (2006, February 13). The New Yorker. Available at: http://gladwell.com/million-dollar-murray

Goering, P.N., Streiner, D.L., Adair, C., Aubry, T., Barker, J., Distasio, J., Hwang, S.W., Komaroff, J., Latimer, E., Somers, J. \& Zabkiewicz, D.M. (2011). The At Home/Chez Soi trial protocol: a pragmatic, multi-site, randomised controlled trial of a Housing First intervention for homeless individuals with mental illness in five Canadian cities, BMJ Open, doi:10.1136/bmjopen-2011-000.

Goering, P., Veldhuizen, S.., Watson, A., Adair, C., Kopp, B., Latimer, E., Nelson, G., MacNaughton, E., Streiner, D. \& Aubry, T. (2014). National final report: cross-site At Home/Chez Soi project. Calgary, AB: Mental Health Commission of Canada. Available at:

http://www.mentalhealthcommission.ca/English/system/files/private/document/mhcc at home repor t national cross-site eng 2.pdf

Goodman, L. (2014, April 8). Study finds new approach to homelessness saves money, keeps people off 
street. Global News. Available at: http://globalnews.ca/news/1257162/study-finds-new-approach-tohomelessness-saves-money-keeps-people-off-street

Hulchanski, J.D. (2009). Homelessness in Canada: past, present future. Conference keynote address, Growing home: housing and homelessness in Canada. University of Calgary. Available at:

http://www.cprn.org/documents/51110 EN.pdf

Hansen, H., Bourgois, P. \& Drucker, E. (2014). Pathologizing poverty: new forms of diagnosis, disability, and structural stigma under welfare reform, Sco Sci Med, 103, 76-83.

Heffernan, Todorow \& Luu. (2015, July 7). Why Housing First won't end homelessness. Rabble. Available at: http://rabble.ca/blogs/bloggers/views-expressed/2015/07/why-housing-first-wont-endhomelessness

Homes for Women Campaign. (2013). Housing First, women second? Gendering Housing First. . Available at: $\underline{\text { http://ywcacanada.ca/data/documents/00000382.pdf }}$

Institute for Children, Poverty \& Homelessness. (2013). A theory of poverty destabilization: why lowincome families become homeless in New York City. Available at:

http://www.icphusa.org/filelibrary/ICPH policybrief ATheoryofPovertyDestabilization.pdf

Jacobs, K. \& Manzi, T. (1996). Discourse and policy change: the significance of language for housing research, Hous Stud, 11(4), 543-560.

Johnsen, S. \& Teixeira, L. (2010). Staircases, elevators and cycles of change: 'Housing First' and other housing models for homeless people with complex support needs. The University of York and Crisis UK. Available at: $\underline{\text { www.crisis.org.uk/data/files/publications/Housing\%20Models\%20Report.pdf }}$

Klodawsky, F. (2009). Home spaces and rights to the city: thinking social justice for chronically homeless women, Urban Geogr, 30(6), 591-610.

Krieger, N. (1994). Epidemiology and the web of causation: has anyone seen the spider? Soc Sci Med, 39(7), 887-903.

Levy, J., Ansara, D. \& Stover, A. (2013). Racialization and health inequities in Toronto. Toronto: Toronto Public Health. 2013. Available at: www.toronto.ca/legdocs/mmis/2013/hl/bgrd/backgroundfile-

62904.pdf

Lewchuk, W., Lafleche, M., Dyson, D., Goldring, L., Meisner, A., Procyk, S., Rosen, D., Shields, J., Viducis, P. \& Vrankulj, S. (2013). It's more than poverty: employment precarity and household well-being.

Retrieved from: www.unitedwaytoronto.com/document.doc?id=91

McQuaig, L. (2007, June 1). We allowed rich to win class war. Toronto Star. Available at: www.thestar.com/opinion/2007/06/01/we allowed rich to win class war.html 
Meyer, I. \& Schwartz, S. (2000). Social issues as public health: promise and peril, Am. J. Public Health, 90(8), 1189-1191.

Monsebraaten, L. (2014, May 31). Ontario's minimum wage jumps to \$11 Sunday. Toronto Star. Available at:

www.thestar.com/news/gta/2014/05/31/ontarios minimum wage jumps to 11 sunday.html

National Coalition for the Homeless. (2002). Poverty versus pathology: What's 'chronic' about homelessness?

Nelson, G., Aubry, T., Lafrance, A. (2007). A review of the literature on the effectiveness of housing and support, assertive community treatment, and intensive case management interventions for persons with mental illness who have been homeless, American Journal of Orthopsychiatry, 77(3), 350-361.

Nolais, J. (2012, November 29). Can Calgary still end homelessness? City's 10-year plan verges on halfway point. Metro. Available at: www.metronews.ca/news/calgary/459678/can-calgary-still-endhomelessness-citys-10-year-plan-verges-on-halfway-point

O'Campo, P., Urquia, M. (2012). Aligning method with theory: a comparison of two approaches to modeling the social determinants of health, Matern Child Health J., 16(9), 1870-8.

Ornstein, M. (2006). Ethno-racial groups in Toronto, 1971 - 2001: a demographic and socio-economic profile. Toronto: Institute for Social Research, York University. Available at:

www.isr.yorku.ca/download/Ornstein--Ethno-Racial Groups in Toronto 1971-2001.pdf

Ostroff, J. (2015, August 13). Canada could end homelessness. And it'll only cost you \$46 a year. Huffington Post. Available at: www.huffingtonpost.ca/2015/08/13/housing-first-federalelection n 7949510.html

Paradis, E., Wilson, R.M. \& Logan, J. (2014). Nowhere else to go: inadequate housing \& risk of homelessness among families in Toronto's aging rental buildings. Cities Centre: University of Toronto. Available at: http://neighbourhoodchange.ca/documents/2014/04/paradis-et-al-2014-nowhere-else-togo-inadequate-housing-risk-of-homelessness-among-families-in-torontos-aging-rental-buildingsrp231.pdf

Pulkingham, J. \& Fuller, S. (2012). From parent to patient: the medicalization of lone motherhood through welfare reform, Social Politics, 19(2), 243-268.

Ratner, S. Inequality, unbelievably, gets worse. (2014, November 16). New York Times. Available at: www.nytimes.com/2014/11/17/opinion/inequality-unbelievably-gets-worse.html? $r=0$

Research Alliance for Canadian Homelessness, Housing and Health. (2010). Housing vulnerability and health: Canada's hidden emergency. Available at: www.crich.ca/reports/housing-vulnerability-health

Schrank, A. (2013, September 26). L.A. puts chronically homeless in the front of housing line. National 
Public Radio. Available at: www.npr.org/2013/09/26/226201549/l-a-puts-chronically-homeless-in-thefront-of-housing-line

Slater, T. (2004). Municipally managed gentrification in South Parkdale, Toronto. The Canadian Geographer, 48(3), 303-325.

Stanhope, V. \& Dunn, K. (2011). The curious case of Housing First: the limits of evidence-based policy. Int J Law Psychiatry, 34(4), 275-82.

Stergiopoulos, V., Dewa, C., Durbin, J., Chau, N., Svoboda, T. (2010). Assessing the Mental Health Service Needs of the Homeless: A Level-of-Care Approach, Journal of Health Care for the Poor and Underserved, 21(3), 1031-1045.

Stergiopoulos, V., Hwang, S., Gozdzik, A., Nisenbaum, R., Latimer, E., Rabouin, E., Adair, C.E., Bourque, J., Connelly, J., Frankish, J., Katz, L.Y., Mason, K., Misir, V., O’Brien, K., Sareen, J., Schütz, C.G., Singer, A., Streiner, D.L., Vasiliadis, H.M. \& Goering, P.N. (2015). Effect of scattered-site housing using rent supplements and intensive case management on housing stability among homeless adults with mental illness: a randomized trial, JAMA, 313(9), 905-915.

Stock, M. Ending homelessness? A critical examination of Housing First in Canada and Winnipeg. (2016). Canadian Centre for Policy Alternatives, Alberta. Available at:

https://www.policyalternatives.ca/publications/reports/ending-homelessness

Swan, M. (2013, November 10). Housing First strategy for homeless extended until 2019. Catholic Register. Available at: www.catholicregister.org/item/17174-housing-first-strategy-for-homeless$\underline{\text { extended-until-2019 }}$

Tsemberis, S., Gulcur L., \& Nakae M. (2004). Housing first, consumer choice and harm reduction for homeless individuals with a dual diagnosis, Am. J. Public Health, 94(4), 651-656.

Tsemberis, S. (2010). Housing First: The Pathways model to end homelessness for people with mental illness and addiction. Center City: Hazelden.

Waegemakers Schiff, J. \& Rook J. (2012). Housing First: where is the evidence? Homeless Hub Press. Retrieved from: www.homelesshub.ca/sites/default/files/HousingFirstReport final.pdf

Wellesley Institute. (2010). Precarious Housing in Canada 2010. Available at: www.wellesleyinstitute.com/wp-content/uploads/2010/08/Precarious Housing In Canada.pdf

Williams, D.R. \& Collins, C. (2001). Racial residential segregation: a fundamental cause of racial disparities in health, Public Health Rep, 116(5), 404-416.

Willse, C. (2010). Neo-liberal biopolitics and the invention of chronic homelessness, Economy and Society, 39(2): 155-184. 